\title{
Changes of the Tropical Tropopause Layer under Global Warming $\mathscr{A}$
}

\author{
PU LIN \\ Program in Atmospheric and Oceanic Sciences, Princeton University, Princeton, New Jersey \\ DAVID PAYNTER, Yi Ming, AND V. RAMASWAMY \\ NOAA/Geophysical Fluid Dynamics Laboratory, Princeton, New Jersey
}

(Manuscript received 16 June 2016, in final form 25 October 2016)

\begin{abstract}
This paper investigates changes in the tropical tropopause layer (TTL) in response to carbon dioxide increase and surface warming separately in an atmospheric general circulation model, finding that both effects lead to a warmer tropical tropopause. Surface warming also results in an upward shift of the tropopause. A detailed heat budget analysis is performed to quantify the contributions from different radiative and dynamic processes to changes in the TTL temperature. When carbon dioxide increases with fixed surface temperature, a warmer TTL mainly results from the direct radiative effect of carbon dioxide increase. With surface warming, the largest contribution to the TTL warming comes from the radiative effect of the warmer troposphere, which is partly canceled by the radiative effect of the moistening at the TTL. Strengthening of the stratospheric circulation following surface warming cools the lower stratosphere dynamically and radiatively via changes in ozone. These two effects are of comparable magnitudes. This circulation change is the main cause of temperature changes near $63 \mathrm{hPa}$ but is weak near $100 \mathrm{hPa}$. Contributions from changes in convection and clouds are also quantified. These results illustrate the heat budget analysis as a useful tool to disentangle the radiative-dynamical-chemical-convective coupling at the TTL and to facilitate an understanding of intermodel difference.
\end{abstract}

\section{Introduction}

The tropical tropopause layer (TTL) is the transition region between the troposphere and the stratosphere (Fueglistaler et al. 2009; Randel and Jensen 2013). As one moves from the troposphere into the stratosphere, static stability sharply increases, convective activities and clouds evanesce, radiative heating rates change from net cooling to net warming, and the meridional circulation shifts from the Hadley circulation into the much wider Brewer-Dobson circulation. Many chemically and/or radiatively important species, including water vapor and ozone, experience sharp gradients in their concentrations across the TTL. The TTL affects both the troposphere and the stratosphere and exerts influences well beyond the tropical region. The thermal

Supplemental information related to this paper is available at the Journals Online website: http://dx.doi.org/10.1175/ JCLI-D-16-0457.s1.

Corresponding author e-mail: Pu Lin, pu.lin@noaa.gov structure of the TTL is of particular interest as it sets the stratospheric water vapor concentration (Mote et al. 1996), changes of which may have contributed to the recent hiatus of surface warming (Solomon et al. 2010). It also affects the climate system through changes of clouds, especially cirrus clouds ( $\mathrm{Li}$ and Thompson 2013; Virts et al. 2010). Recent studies have also suggested a possible link between the TTL temperature and the intensity of tropical cyclones (Emanuel et al. 2013; Wang et al. 2014).

The thermal structure of the TTL is an emergent property of the complex coupling among convection, radiation, and circulations of various scales (Fueglistaler et al. 2009; Randel and Jensen 2013, and references therein). It can be altered by climate change in multiple ways, which involve changes in temperature outside the TTL; concentrations of water vapor, ozone, and greenhouse gases (GHGs); cloud properties; circulation patterns; and convective activities. Given the subtle nature of the balance among all these factors, it might be surprising that almost all general circulation models (GCMs) and chemistry-climate models (CCMs) predict a 
warming and upward-shifting trend of the tropical tropopause over the twenty-first century (Gettelman et al. 2010; Kim et al. 2013).

Shepherd (2002) proposed a conceptual model to explain the tropopause change, which postulates a warmer and higher tropopause when the troposphere warms, but a colder and higher tropopause when the stratosphere cools (both of which would occur as GHGs increase). This relationship has been confirmed with observations (Seidel and Randel 2006) and simulations (Santer et al. 2003). Based on linear regression analysis, Austin and Reichler (2008) attributed the tropopause changes from 1960 to 2100 to changes in the BrewerDobson circulation, stratospheric ozone, and sea surface temperatures (SSTs). However, because of the highly coupled nature of the TTL processes, it is hard to avoid ambiguity in regression-based attribution analyses. Previous mechanistic studies investigated the radiative balance of the TTL and its sensitivity to changes in the radiatively active species (Thuburn and Craig 2002; Gettelman et al. 2004). These radiative transfer calculations were, however, done in a relatively simplistic fashion, and the coupling between the species and circulation was largely neglected.

In this paper, we seek a more complete understanding of the simulated warming trends at the TTL as GHGs increase. By analyzing the heat budget at the TTL, we disentangle the coupled radiative, dynamic, and thermodynamic processes and quantify the contribution from each process. The organization of the paper is as follows. Section 2 describes the experiment setup and the methodology for the heat budget analysis. The main results are presented in section 3. A discussion on the robustness of the results is given in section 4 , which is followed by a summary and conclusion in section 5 .

\section{Methodology}

\section{a. Model simulations}

We conduct three pairs of idealized perturbation experiments using the Geophysical Fluid Dynamics Laboratory (GFDL) Atmospheric Model, version 3 (AM3; Donner et al. 2011), the atmospheric component of the coupled GFDL Climate Model, version 3 (CM3). This model has 48 vertical layers with a model top at $0.01 \mathrm{hPa}$ $(\sim 86 \mathrm{~km})$, of which 7 layers are between 40 and $200 \mathrm{hPa}$. Note that AM3 incorporates an interactive chemistry scheme in both the stratosphere and troposphere, thus allowing ozone to be transported by circulation and to adjust to the corresponding climate. Basic simulation characteristics of this model are documented in Donner et al. (2011). We specify the sea surface temperatures and the concentration of carbon dioxide $\left(\mathrm{CO}_{2}\right)$ in the experiments. As the first perturbation, we quadruple the $\mathrm{CO}_{2}$ concentration from $368 \mathrm{ppm}$ in the control experiment to $1472 \mathrm{ppm}(4 \times \mathrm{CO} 2)$. As the second perturbation, we uniformly increase SST by $4 \mathrm{~K}$ from the present-day climatology in the control (4KSST). As the third perturbation, we apply both quadrupling $\mathrm{CO}_{2}$ and a 4-K increase of SST (COMBINE). All other external forcings remain the same. Each simulation is run for 11 model years, and we analyze the last 10 years. All results are averaged over the tropics $\left(20^{\circ} \mathrm{S}-20^{\circ} \mathrm{N}\right)$. Zonal mean temperature and zonal wind changes in these experiments are shown in the supplemental material.

\section{b. Heat budget analysis}

The thermodynamic equation of the atmosphere can be written as follows:

$$
\frac{\partial \theta}{\partial t}=Q_{\mathrm{dyn}}+Q_{\mathrm{conv}}+Q_{\mathrm{rad}},
$$

in which $Q_{\text {dyn }}, Q_{\text {conv }}$, and $Q_{\text {rad }}$ represent the potential temperature tendency $\partial \theta / \partial t$ driven by advection, phase change of water, and radiation, respectively. In a quasiequilibrium climate state, $Q_{\mathrm{dyn}}, Q_{\text {conv }}$, and $Q_{\text {rad }}$ effectively balance each other out, resulting in $\partial \theta / \partial t=0$. Now considering the difference between two climate states, we will have

$$
\Delta Q_{\mathrm{dyn}}+\Delta Q_{\mathrm{conv}}+\Delta Q_{\mathrm{rad}}=0 .
$$

We further decompose $\Delta Q_{\text {rad }}$ into terms due to different controlling factors:

$$
\begin{aligned}
\Delta Q_{\mathrm{rad}} & =\frac{\partial Q_{\mathrm{rad}}}{\partial T_{\mathrm{loc}}} \Delta T_{\mathrm{loc}}+\sum_{i} \frac{\partial Q_{\mathrm{rad}}}{\partial X_{i}} \Delta X_{i} \\
& =\Delta Q_{\mathrm{rad}, T_{\mathrm{loc}}}+\sum_{i} \Delta Q_{\mathrm{rad}, X_{i}}
\end{aligned}
$$

in which $T_{\text {loc }}$ is the temperature at the location of interest and $X_{i}$ includes concentrations of radiatively active species (such as ozone, water vapor, and GHGs), clouds, and nonlocal temperature. Changes in these species and clouds may be caused by variations in largescale circulation or convection. Then Eq. (2) can be written as

$$
-\Delta Q_{\mathrm{rad}, T_{\mathrm{loc}}}=\Delta Q_{\mathrm{dyn}}+\Delta Q_{\mathrm{conv}}+\sum_{i} \Delta Q_{\mathrm{rad}, X_{i}}
$$

Note that in the much simplified Newtonian cooling framework, the left-hand side of the above equation would correspond to $\Delta T_{\mathrm{loc}} / \tau$, where $\tau$ is the radiative relaxation time, which is $\sim 30$ days in the TTL (Hartmann et al. 2001). When an atmosphere layer becomes warmer, 
it will emit more longwave radiation. To sustain the warming, there must be additional heating from dynamical, convective, or other radiative processes to balance the increased longwave emission. Equation (4) helps quantify the contributions of different physical processes to the changes in the TTL temperature.

\section{c. Estimation of heating rates}

The variables $Q_{\text {dyn }}, Q_{\text {conv }}$, and $Q_{\text {rad }}$ are readily archived in the model output. Since $Q_{\mathrm{dyn}}$ is largely brought about by the vertical transport of the Brewer-Dobson circulation in the TTL region, it can be approximated by $-\bar{\theta}_{z} \bar{w}^{*}$, in which $\bar{\theta}_{z}$ is the vertical derivative of zonal mean potential temperature, and $\bar{w}^{*}$ is the transformed Eulerian mean (TEM) vertical velocity (Rosenlof 1995; Yang et al. 2008). We also calculate $\bar{\theta}_{z}$ and $\bar{w}^{*}$ from other model outputs to further decompose the total $\Delta Q_{\text {dyn }}$ into those caused by $\Delta \bar{\theta}_{z}$ and $\Delta \bar{w}^{*}$.

To estimate the individual radiative heating rates, we employ the offline version of the radiative transfer model used in AM3 (Freidenreich and Ramaswamy 1999; Schwarzkopf and Ramaswamy 1999; Anderson et al. 2004). The radiative heating rate change due to each perturbation $\Delta Q_{\mathrm{rad}, X_{i}}$ is calculated using the partial radiative perturbation method (Wetherald and Manabe 1988) (note that $\Delta Q_{\mathrm{rad}, T_{\mathrm{loc}}}$ is computed in the same way as $\left.\Delta Q_{\operatorname{rad}, X_{i}}\right)$. We perform a two-sided perturbation to minimize the influence of the decorrelation perturbation (Colman and McAvaney 1997; Soden et al. 2008), that is,

$$
\begin{aligned}
\Delta Q_{\mathrm{rad}, X_{i}}= & \frac{1}{2}\left[Q_{\mathrm{rad}}\left(X_{i}^{P}, X_{j \neq i}^{C}\right)-Q_{\mathrm{rad}}\left(X_{i}^{C}, X_{j \neq i}^{C}\right)\right. \\
& \left.+Q_{\mathrm{rad}}\left(X_{i}^{P}, X_{j \neq i}^{P}\right)-Q_{\mathrm{rad}}\left(X_{i}^{C}, X_{j \neq i}^{P}\right)\right],
\end{aligned}
$$

in which $X^{C}$ and $X^{P}$ stand for radiation-relevant variables from the control simulation, and the perturbed simulation, respectively. The offline radiative transfer is performed every $3 \mathrm{~h}$ at each model grid using the instantaneous temperature, water vapor, ozone, and cloud fields archived from the GCM simulations. To reduce computational cost, we construct a synthetic 1 -yr time series by randomly sampling the entire $10-\mathrm{yr}$ simulation. The averaged radiative heating rates calculated from these 1-yr profiles are very close to the 10 -yr averages. The clouds in AM3 are either explicitly resolved or parameterized by shallow and deep cumulus schemes. Both types are seen by radiation. Cloud overlap is treated using the Monte Carlo independent column approximation (Pincus et al. 2003). The cloud droplet size is calculated from the prognostic cloud water content and droplet number concentration. The cloud ice particle size is parameterized as a function of temperature. More details can be found in Donner et al. (2011).

For perturbations in temperature and water vapor, instead of perturbing the whole profile at once, we perturb the tropospheric, TTL, and stratospheric parts separately, as the governing physics vary for these regions. We defined the tropospheric region as the model layers below the level of zero net clear-sky radiative heating (LZRH), the stratospheric region as the model layers above the cold-point tropopause, and the TTL as the layers between. For the control and perturbed simulations, we calculated the pressure of the cold-point tropopause from the tropical mean climatology, and use the lower of these two values as the TTL top boundary. Similarly to define the bottom boundary, we use the highest pressure LZRH of the two simulations.

\section{Results}

Figure 1 shows the tropical-averaged temperature profiles in our simulations. We also mark the tropopause levels based on different definitions: the LZRH, the World Meteorological Organization (WMO)-defined tropopause where the lapse rate equals $2 \mathrm{~K} \mathrm{~km}^{-1}$, and the cold-point tropopause where the lapse rate is zero. It is clear from Fig. 1 that the tropical tropopause warms significantly in both experiments. In the $4 \times \mathrm{CO} 2$ case, the troposphere warms slightly, and the strongest warming is located around $90 \mathrm{hPa}$. The tropics cool above $\sim 70 \mathrm{hPa}$, and the strongest cooling occurs roughly at the stratopause. The cold-point tropopause remains at $\sim 90-\mathrm{hPa}$ level, and warms by $0.8 \mathrm{~K}$. In the $4 \mathrm{KSST}$ case, the tropics warm below $\sim 80 \mathrm{hPa}$ and cool above. The strongest warming is located in the upper troposphere around $200 \mathrm{hPa}$, and the strongest cooling is in the lower stratosphere around $60 \mathrm{hPa}$. The cold-point tropopause is lifted from 90 to $77 \mathrm{hPa}$, and the cold-point temperature warms by $1.4 \mathrm{~K}$. In the COMBINE case in which $\mathrm{CO}_{2}$ and SST change simultaneously, the resulted temperature change profile matches with the sum of those from $4 \times \mathrm{CO} 2$ and $4 \mathrm{KSST}$ perturbations, with the cold-point temperature warmed by $2.2 \mathrm{~K}$. This is in agreement with previous studies by Kodama et al. (2007) and Kawatani et al. (2012), who also found negligible nonlinearity in stratospheric circulation responses to both $\mathrm{CO}_{2}$ and SST increase.

Note that, on average, the CMIP5 models under RCP8.5 predict a cold-point tropopause warming of $\sim 1.5 \mathrm{~K}$ (Kim et al. 2013). Gettelman et al. (2010) showed that most CCMs simulate a 0.5-1.0-K warming of the cold point over the twenty-first century. Given a typical tropical coldpoint temperature of $190 \mathrm{~K}$, a $1-\mathrm{K}$ warming at the cold point would lead to $\sim 18 \%$ or $0.6 \mathrm{ppmv}$ increase of stratospheric water vapor concentration, assuming that 

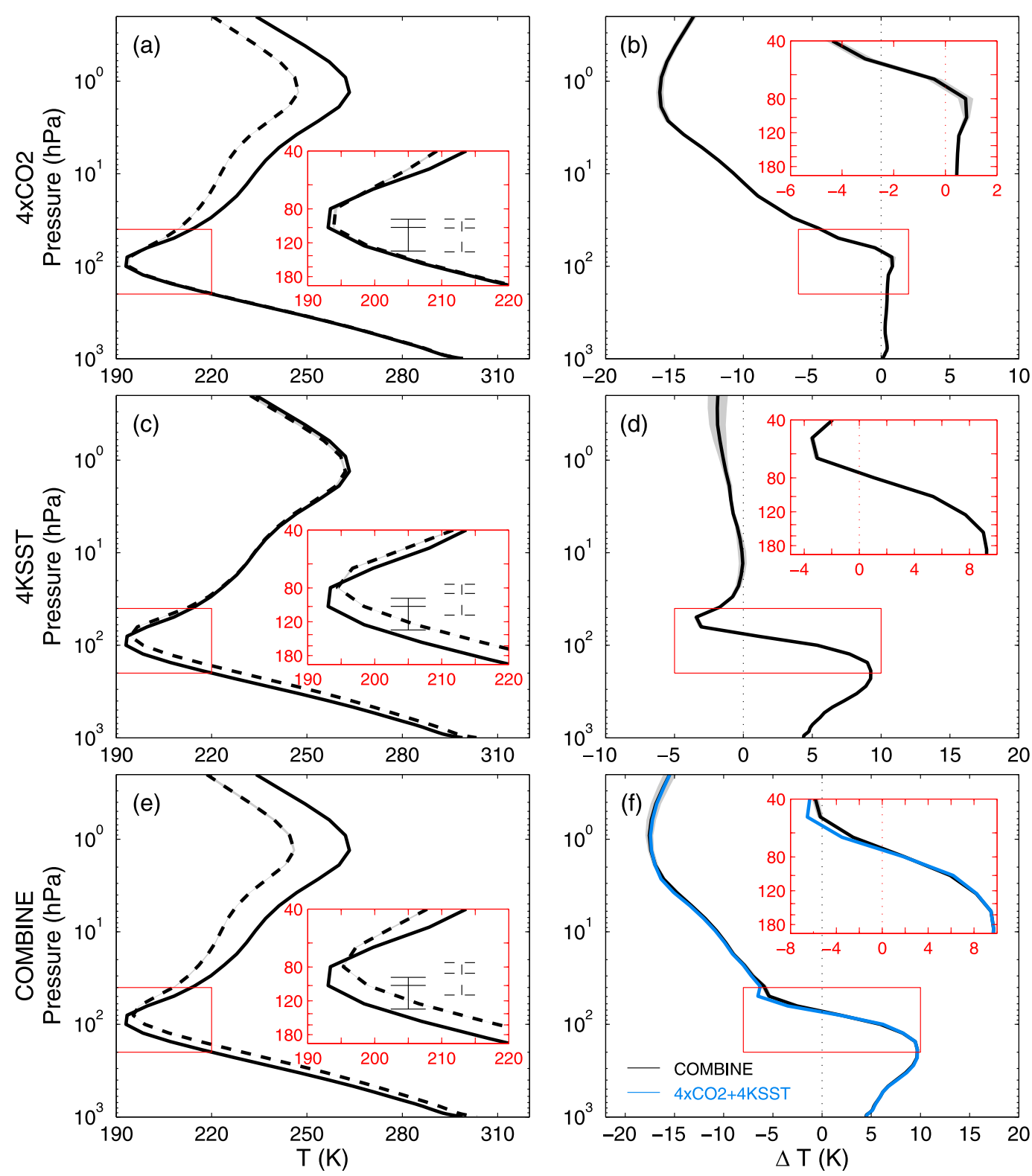

FIG. 1. (a) Tropical mean temperature profiles in the control (solid) and $4 \times \mathrm{CO} 2$ (dashed) experiments. The horizontal bars mark the tropopauses based on different definitions. From bottom to top are the LZRH tropopause, the WMO tropopause, and the cold-point tropopause. (b) Tropical mean profile of temperature difference for $4 \times \mathrm{CO} 2$. Gray shading plots the $95 \%$ confidence interval based on the Student's $t$ test. (c),(d) As in (a),(b), but for 4KSST. (e),(f) As in (a),(b), but for COMBINE. Blue line in (f) plots the sum of temperature change from the $4 \times \mathrm{CO} 2$ and $4 \mathrm{KSST}$ experiments.

the stratospheric water vapor concentration is equal to the saturation concentration at the cold point.

Compared to simulations with more realistic forcings, these idealized experiments provide a relatively clean setting to explore the TTL changes. At the same time, the fully interactive ozone, water vapor, and clouds in this model make it possible to study a full range of responsible physical processes, and to assess their relative contributions. We focus on the $4 \times \mathrm{CO} 2$ and 4 KSST cases in the following text since the COMBINE case can be largely explained by the sum of the two. Also note that these two cases represent changes occurring at different time scales. Adjustments of the climate system to $\mathrm{CO}_{2}$ increase that are independent from surface temperature changes would be much faster than those mediated by changes in surface temperature (Sherwood et al. 2015). 
Temperature $(\mathrm{K})$

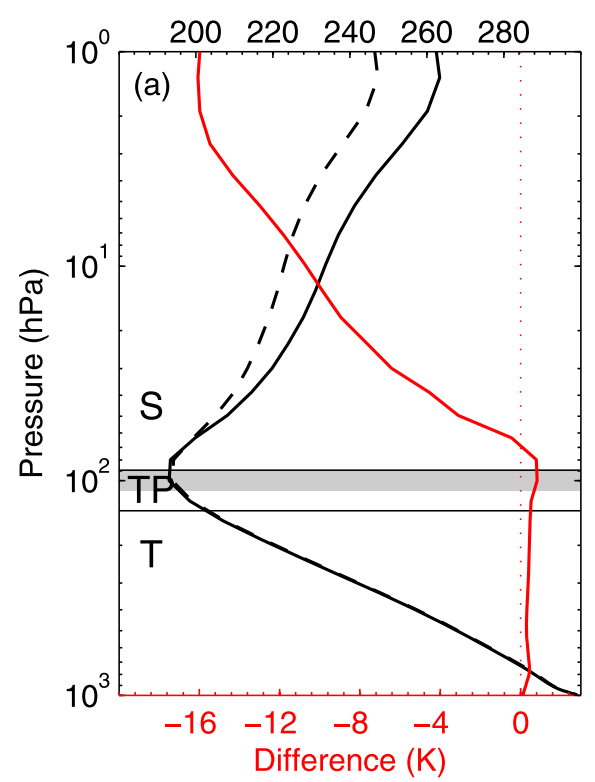

Ozone (ppmm)

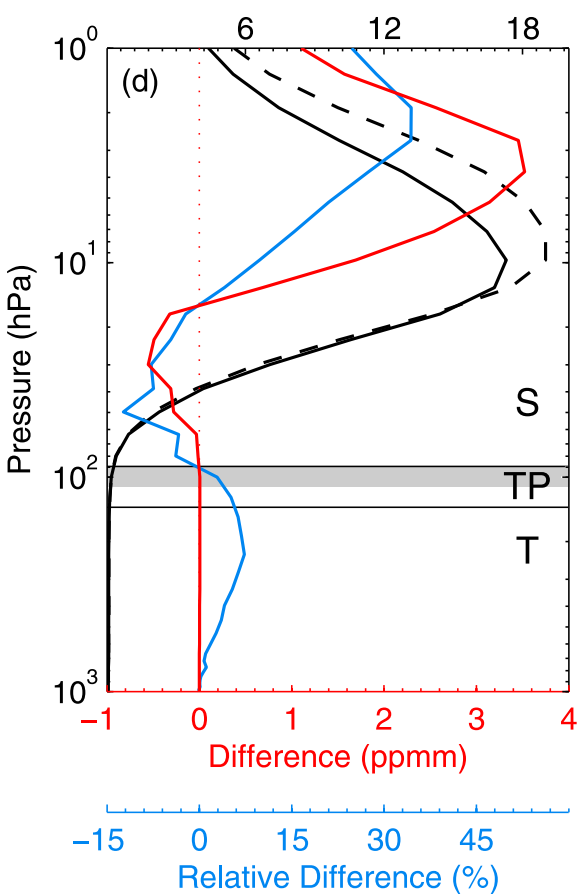

Water Vapor $(\mathrm{kg} / \mathrm{kg})$
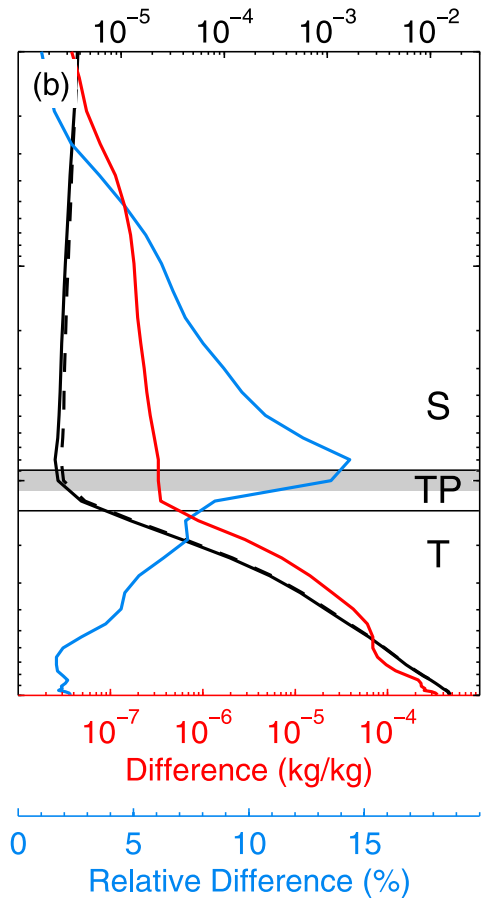

Cloud Fraction
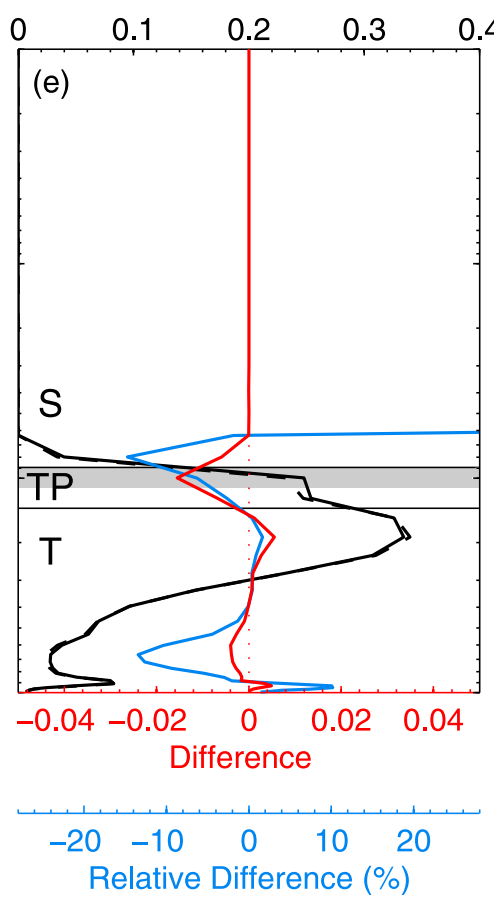

Relative Humidity (\%)
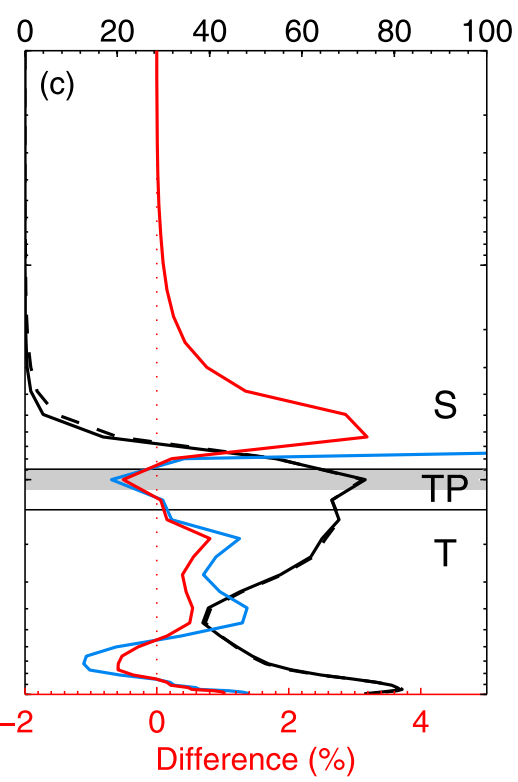

Relative Difference (\%) $\mathrm{W}^{*}(\mathrm{~mm} / \mathrm{s})$

\section{$\begin{array}{rrrrrr}4 & 0 & 0.5 & 1 & 1.5 & 2\end{array}$}
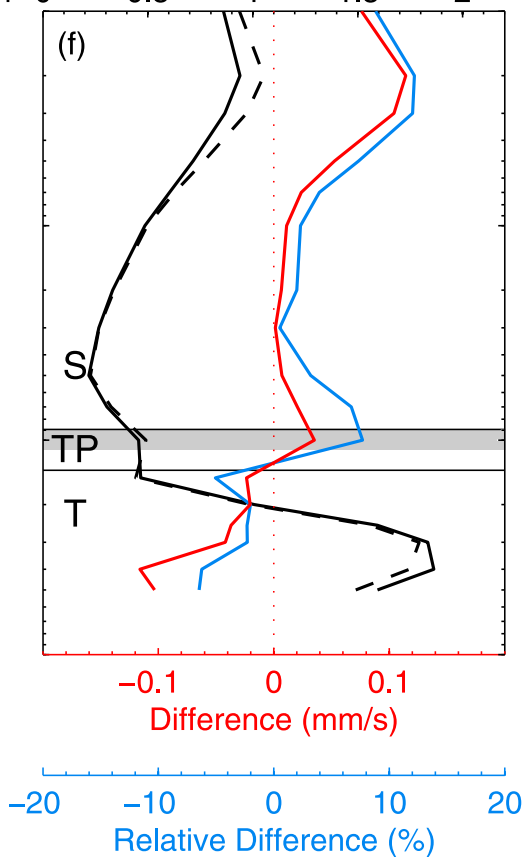

FIG. 2. Tropical mean profiles of (a) temperature, (b) specific humidity, (c) relative humidity, (d) ozone concentration, (e) cloud fraction, and (f) the TEM vertical velocity. Black solid lines are from the control simulation, dashed lines are from the perturbed simulation, red lines are the difference between the control and $4 \times \mathrm{CO} 2$ experiments, and blue lines show the relative difference. The gray shading indicates the $100-\mathrm{hPa}$ layer for which a detailed heat budget analysis is performed. The horizontal lines mark the boundaries separating the stratosphere, the tropopause layer, and the troposphere. 


\section{a. $4 \times \mathrm{CO} 2$ case}

Figure 2 illustrates changes of some key parameters in this experiment. With quadrupling $\mathrm{CO}_{2}$, the middle and upper stratosphere radiatively cool up to $17 \mathrm{~K}$, which is in agreement with many previous studies (e.g., Manabe and Wetherald 1967; Fels et al. 1980; Ramaswamy et al. 1996; Shine et al. 2003). The troposphere warms $\sim 0.3 \mathrm{~K}$ following the warming of the land. Water vapor concentration increases by a few percent in the troposphere, while the relative humidity decreases by $\sim 0.5 \%$ near 100 and $700 \mathrm{hPa}$ and increases in the middle troposphere. What is less recognized by previous studies is the $\sim 0.8-\mathrm{K}$ warming at the cold-point tropopause. Stratospheric water vapor concentration increases as the tropopause warms. The moistening amounts to $14 \%$ just above the cold point, and reduces to a few percent in the upper stratosphere. The increase of the relative humidity peaks at $\sim 3 \%$ in the lower stratosphere. Tropical upwelling from the Brewer-Dobson circulation enhances with the increase of $\mathrm{CO}_{2}$, consistent with previous studies (Oman et al. 2009; Kodama et al. 2007). The acceleration is stronger in the upper stratosphere than elsewhere. More interestingly, the upwelling at the tropopause also increased. This increased upwelling across the tropopause dilutes lower-stratospheric ozone. In contrast, ozone increases in the middle and upper stratosphere, mainly due to a slower photochemical destruction at colder temperature (Barnett et al. 1975). The model also simulates a small increase of ozone below $100 \mathrm{hPa}$. Consistent with changes in the relative humidity, clouds decrease at the tropopause and in the lower troposphere. The reduction of low-level clouds in response to $\mathrm{CO}_{2}$ increase has been reported by many previous studies (e.g., Andrews and Forster 2008; Colman and McAvaney 2011; Zelinka et al. 2013), while less attention has been paid to changes of clouds near the tropopause.

All the changes discussed above may potentially influence the heat budget at the TTL. Their contributions are depicted in Figs. 3 and 4. As shown in Fig. 3, the longwave cooling arising from the warmer tropopause is balanced almost entirely by $\sum_{i} \Delta Q_{\mathrm{rad}, X_{i}}$ in the $4 \times \mathrm{CO} 2$ case, with negligible contributions from $\Delta Q_{\text {dyn }}$ and $\Delta Q_{\text {conv }}$. It is clear from Fig. 4 that the warming at $100 \mathrm{hPa}$ is driven mostly by the direct radiative effect of higher $\mathrm{CO}_{2}$ concentration. As shown in Thuburn and Craig (2002), this radiative heating from $\mathrm{CO}_{2}$ exists due to the strong curvature of the temperature profile near the tropopause. Since longwave emission is proportional to the fourth power of the temperature at which it occurs, the cold tropopause implies that the radiative flux emitted from the tropopause would be smaller than that from layers above and below. When $\mathrm{CO}_{2}$ increases, the stronger

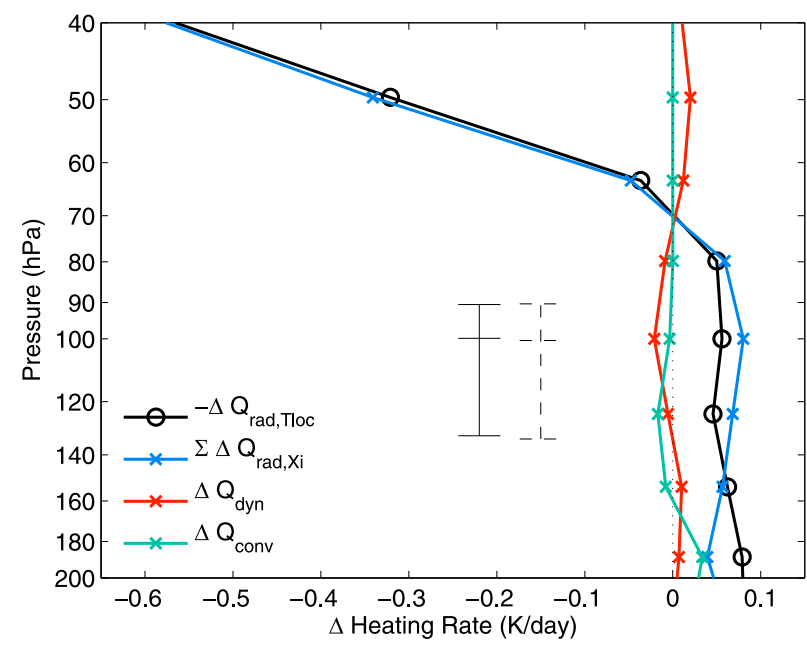

FIG. 3. Profiles of heating rate changes in the upper troposphere/ lower stratosphere for $4 \times \mathrm{CO} 2$. Markers indicate the centers of model layers. The horizontal bars mark the tropopauses based on different definitions as in Fig. 1.

absorption of radiative fluxes at the tropopause from atmospheric layers above and below exceeds the stronger emission from the tropopause. Hence a net longwave heating arises there. Note that $\mathrm{CO}_{2}$ also absorbs at a few shortwave bands (e.g., Liou 2002). The absorption at these shortwave bands contributes to the radiative heating at the TTL as well. The radiative warming from $\mathrm{CO}_{2}$ increase is also reported by McLandress et al. (2014).

The colder stratosphere, which also results from increased $\mathrm{CO}_{2}$ (e.g., Manabe and Wetherald 1967; Shine et al. 2003), tends to cool the tropopause radiatively. The enhanced upwelling across the tropopause produces a dynamical cooling. The radiative effects of the changes in tropospheric temperature, ozone, water vapor, and clouds are much smaller than the direct radiative heating from $\mathrm{CO}_{2}$. The fact that the summation of individual heating rates agrees well with the estimation obtained by subtracting $\Delta Q_{\mathrm{rad}, T_{\mathrm{loc}}}$ from model-diagnosed $\Delta Q_{\mathrm{rad}}$ serves as a validation of our offline radiative transfer calculations (Fig. 4b).

\section{b. 4 KSST case}

The changes of some key variables from the 4KSST experiment are shown in Fig. 5. Compared to the $4 \times \mathrm{CO} 2$ experiment, dynamics and convection play more important roles in the 4KSST experiment (Fig. 6). The composition of the heat budget varies with height. We choose to focus on two levels, 63 and $100 \mathrm{hPa}$, since opposite temperature changes are seen at them. The detailed heat budgets are given in Fig. 7.

The tropical troposphere follows the moist adiabatic lapse rate. As a result, the troposphere warms more than 


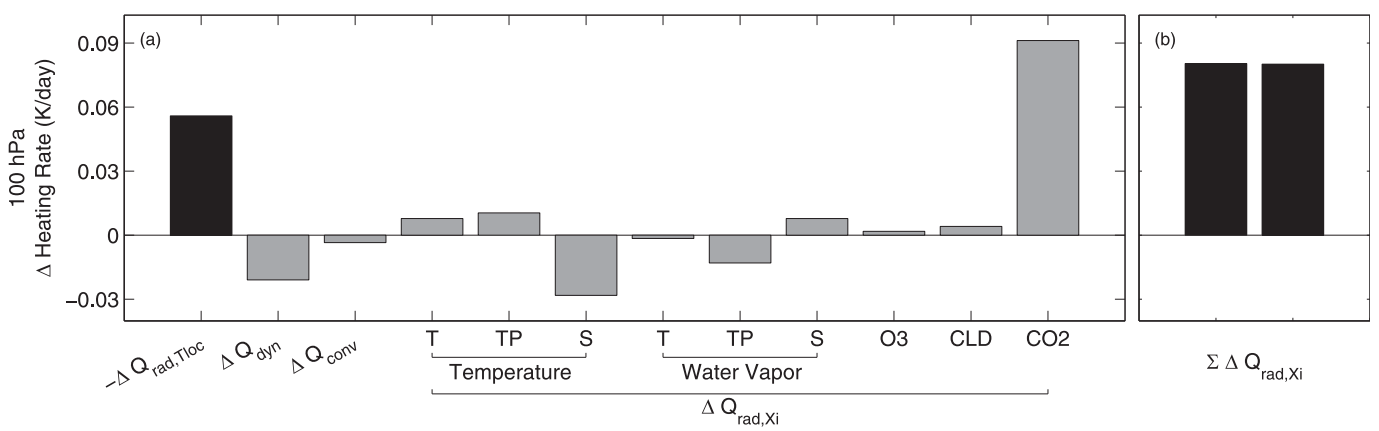

FIG. 4. (a) The radiative cooling from 100 -hPa temperature changes (i.e., $-\Delta Q_{\mathrm{rad}, T_{\mathrm{loc}}}$ ), and heating rate changes due to advection (i.e., $\Delta Q_{\text {dyn }}$ ), latent heat release (i.e., $\Delta Q_{\text {conv }}$ ), and radiative perturbations (i.e., $\Delta Q_{\operatorname{rad}, X_{i}}$ ) at $100 \mathrm{hPa}$ for $4 \times \mathrm{CO} 2$. The radiative perturbations include temperature and water vapor changes in the troposphere (T), the TTL (TP), and the stratosphere (S); changes in ozone concentration (O3); clouds (CLD); and carbon dioxide concentration (CO2). (b) Heating rate changes from all radiative perturbations estimated by (left) summing each individual perturbations from the offline calculations and (right) subtracting $\Delta Q_{\mathrm{rad}, T_{\mathrm{loc}}}$ from modulediagnosed $\Delta Q_{\text {rad. }}$. See text for more explanation.

the surface (Fig. 5a) and tends to warm the atmospheric layers above by emitting more longwave radiation. This effect accounts for the strongest warming tendency at $100 \mathrm{hPa}$ (Fig. 7b) but is relatively weak at $63 \mathrm{hPa}$ (Fig. 7a). The tropospheric warming is accompanied by moistening, which causes a weak radiative cooling at both levels.

The Brewer-Dobson circulation is expected to strengthen in a warmer climate (e.g., Butchart 2014; Lin et al. 2015). This is confirmed by the stronger vertical velocity (Fig. 5f). The enhanced upwelling would have a tendency to cool the atmosphere adiabatically. It is, however, important to note that this dynamic cooling is mediated by changes in the static stability (Fueglistaler et al. 2011). In the 4KSST experiment, the tropopause shifts upward and the static stability decreases near the original tropopause. The effect of decreased static stability dominates that of stronger upwelling at $100 \mathrm{hPa}$, resulting in a weakly positive heating rate. This is in contrast to $\Delta Q_{\text {dyn }}$ being the largest cooling term at $63 \mathrm{hPa}$. The stronger Brewer-Dobson circulation also transports more tropospheric air into the stratosphere and dilutes the ozone concentration in the lower stratosphere. The radiative effect from the decreased ozone is the second largest cooling term at $63 \mathrm{hPa}$, but is negligible at $100 \mathrm{hPa}$. The colder stratosphere has a cooling effect on the tropopause.

As the lower stratosphere cools and the upper troposphere warms, the tropopause shifts upward, allowing convection to penetrate deeper and clouds to form at higher levels. The upward shift of clouds in response to surface warming is a robust feedback mechanism (Hartmann and Larson 2002; Zelinka and Hartmann 2010). The latent heat release from the deeper convection and the radiative effect of cloud changes each contribute about a fifth of the heating that is needed for sustaining the warming at $100 \mathrm{hPa}$. Their effects are negligible at $63 \mathrm{hPa}$ since most convection and clouds are confined below. Water vapor concentration increases by about $50 \%$ in the lower stratosphere due to a warmer cold point as well as stronger convection overshoot. At $100 \mathrm{hPa}$, the moistening of the TTL causes the strongest cooling, but the stratospheric moistening leads to a weak warming. Neither has any appreciable impact on the temperature change at $63 \mathrm{hPa}$.

Since the tropopause has been lifted considerably in this case, the above analysis on the fixed pressure levels cannot answer the question of what causes the warming at the tropopause. To answer this question, we repeat the above analysis in the coordinate of relative height to the WMO tropopause (Birner et al. 2002; Pan et al. 2004). We first identify the WMO tropopause from the temperature profile at each grid and time step. We then shift the profiles of all radiation-relevant variables at this grid and time step by $\Delta z=-H \ln \left(P_{\mathrm{TP}} / P_{\text {ref }}\right)$, where $H$ is the scale height, $P_{\mathrm{TP}}$ is the WMO tropopause pressure, and reference pressure $P_{\text {ref }}=100 \mathrm{hPa}$. These shifted profiles are then used for the offline radiative transfer calculation. The model-diagnosed daily heating rates are converted to the tropopause-relative coordinate in the same way. Note that the conversion between the coordinates leads to deviations of the offline radiative calculations from the model-diagnosed one, and hence the resulted heat budget in this case is not fully closed.

Figure 8 shows the radiative and dynamical properties in the tropopause-relative coordinate. Similar to what is shown in the original log pressure coordinate, water vapor increases in both the stratosphere and troposphere, clouds shift upward, and the upward transport is enhanced in the TTL region (although with smaller magnitudes). However, changes in temperature and ozone are different in the tropopause-relative 

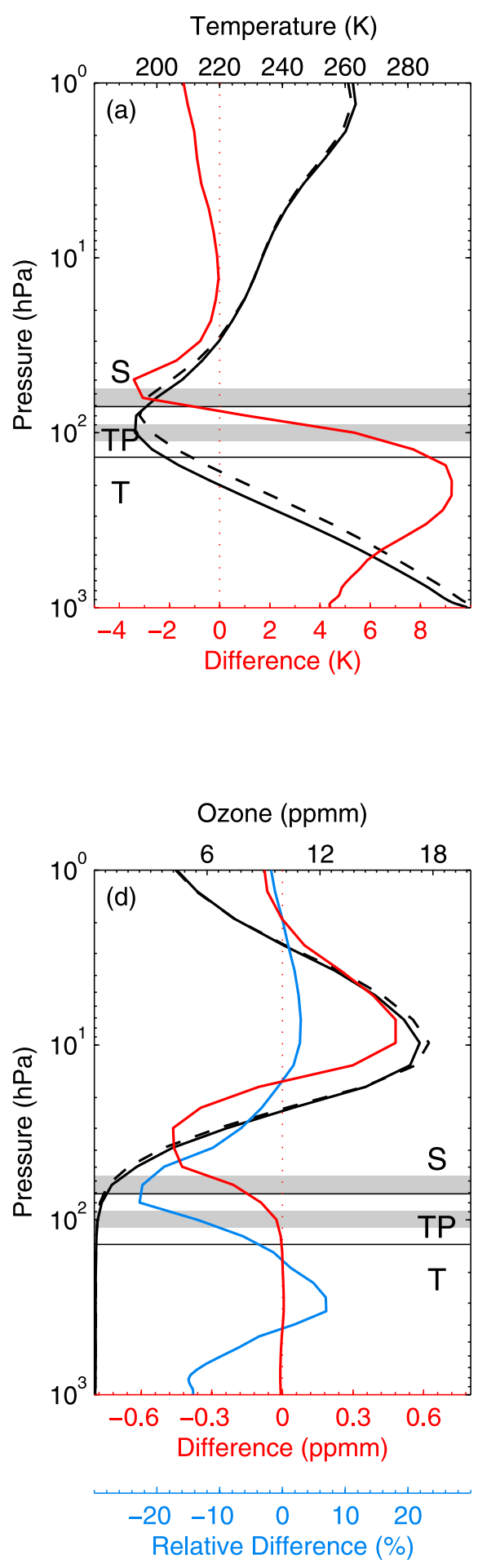
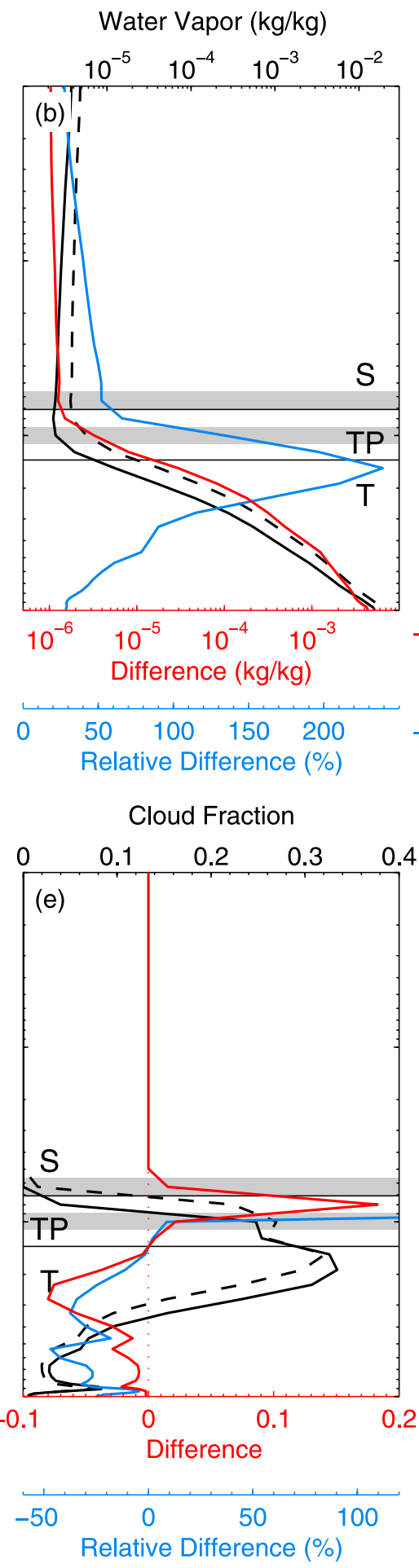

0.40

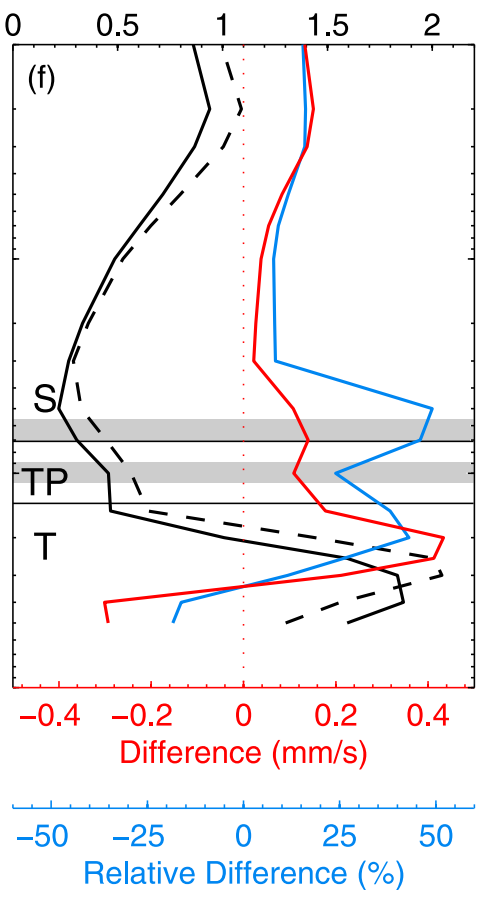

FIG. 5. As in Fig. 2, but for 4KSST.

coordinate compared to the pressure coordinate. Here warming is seen not only in the troposphere but also in the lower stratosphere. Ozone concentration increases rather than decreases in the lower stratosphere.
The heat budget at the composited tropopause is shown in Fig. 9. As shown in the figure, changes in temperature, ozone, clouds, and convection all lead to a warmer tropopause, with the largest contribution coming 


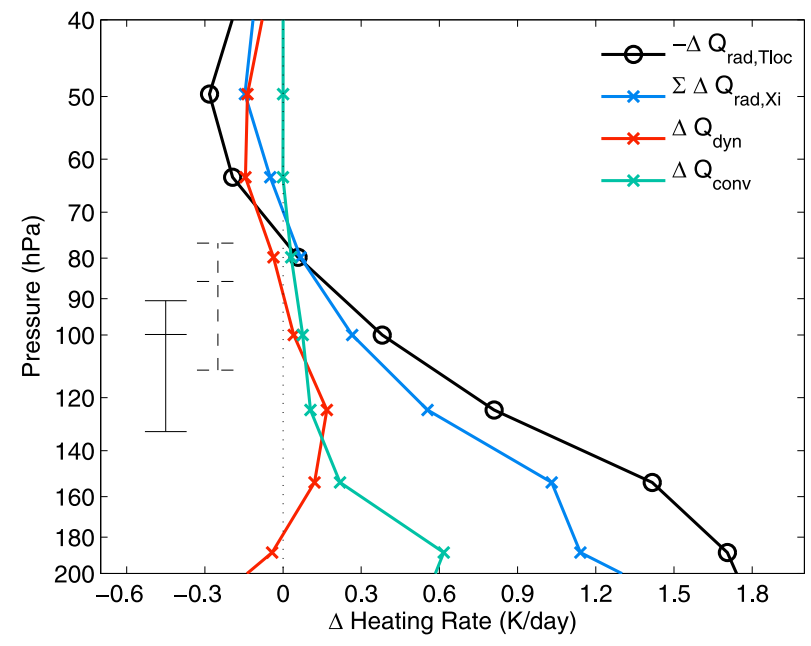

FIG. 6. As in Fig. 3, but for 4KSST.

from the warmer troposphere. The tropopause is cooled by the stronger upwelling as well as moistening in the troposphere and at the tropopause. The largest cooling effect comes from the moistening at the tropopause. The two estimates of $\sum \Delta Q_{\mathrm{rad}, X_{i}}$ differ by about $15 \%$.

\section{Discussion}

Our heat budget analysis suggests that the radiative effect from tropospheric warming and the direct radiative effect from $\mathrm{CO}_{2}$ increase are the two largest contributing factors to the tropopause warming. They are countered mainly by the strengthening of the stratospheric circulation and the moistening near the tropopause. But the magnitudes of the cooling from circulation changes and moistening are in general weak at the tropopause. This may explain why most models show a warmer tropopause under global warming. In practice, the magnitudes of the tropopause warming vary vastly from model to model (Gettelman et al. 2010; Kim et al. 2013). The heat budget analysis shown here would be useful for identifying the sources of intermodel spread. We leave a quantitative assessment of the intermodel spread to future work, but offer a qualitative discussion below.

The direct radiative warming at the tropopause from increased $\mathrm{CO}_{2}$ varies with both the $\mathrm{CO}_{2}$ base value as well as details of the radiative transfer model. Figure 10 shows the increases in longwave and shortwave heating rates at the tropopause as $\mathrm{CO}_{2}$ concentration increases from 200 to $1600 \mathrm{ppm}$. These heating rates are calculated using AM3's radiative transfer codes; two more sophisticated radiative transfer models, namely the $\mathrm{Fu}-\mathrm{Liou}$ model (Fu and Liou 1992) and the Rapid Radiative Transfer Model (RRTM; Mlawer et al. 1997; Clough et al. 2005); and the Reference Forward Model (RFM; http:// www.atm.ox.ac.uk/RFM) line-by-line code, which is the most accurate. The calculation is done for the tropicalaveraged profiles at the equinox from the control experiment. Only clear-sky and aerosol-free results are shown. The shortwave heating rate varies roughly linearly with logarithmic increase of $\mathrm{CO}_{2}$. Different radiative transfer models agree relatively well for the shortwave heating

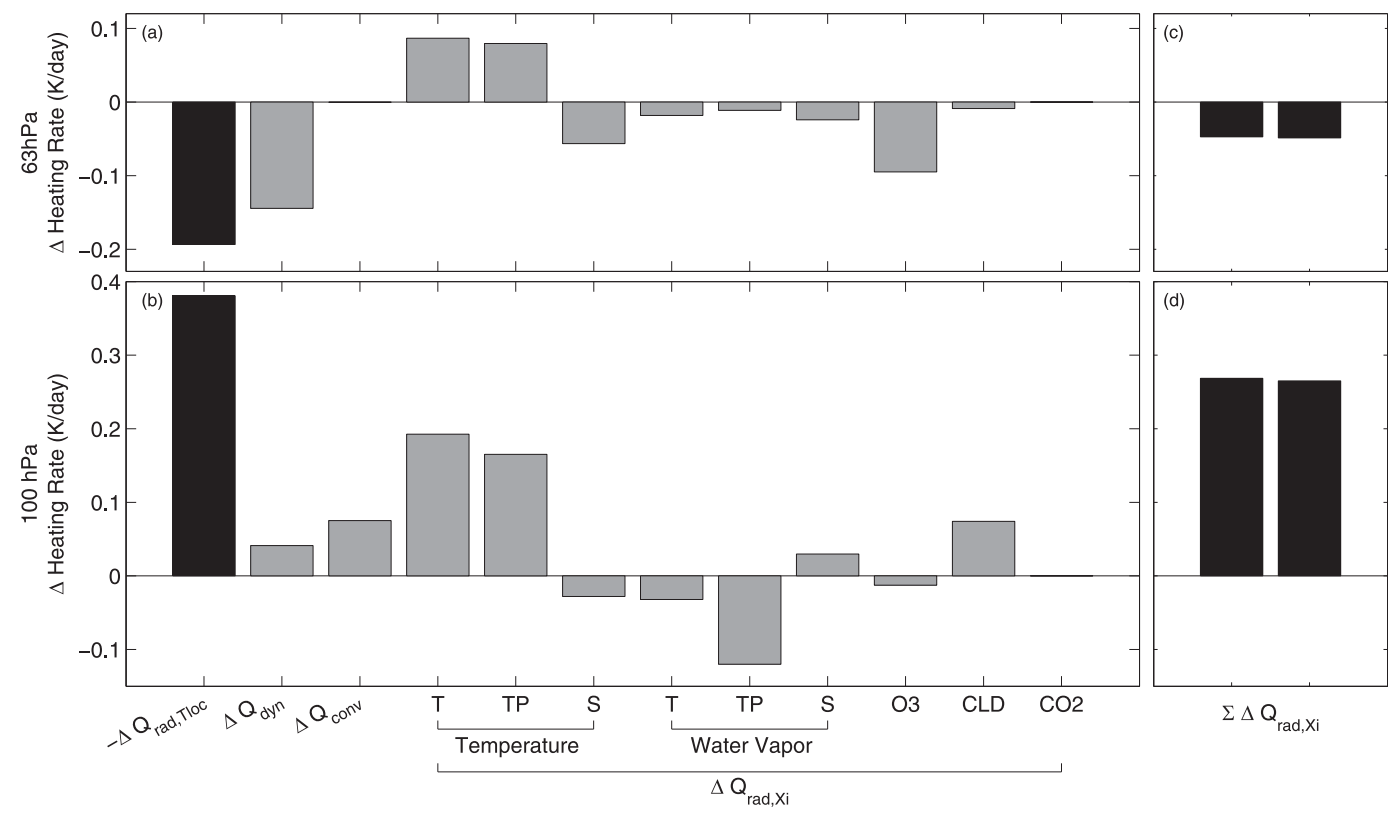

FIG. 7. As in Figs. 4a,b, but for the (a),(c) 63- and (b),(d) 100-hPa layers for 4KSST. 

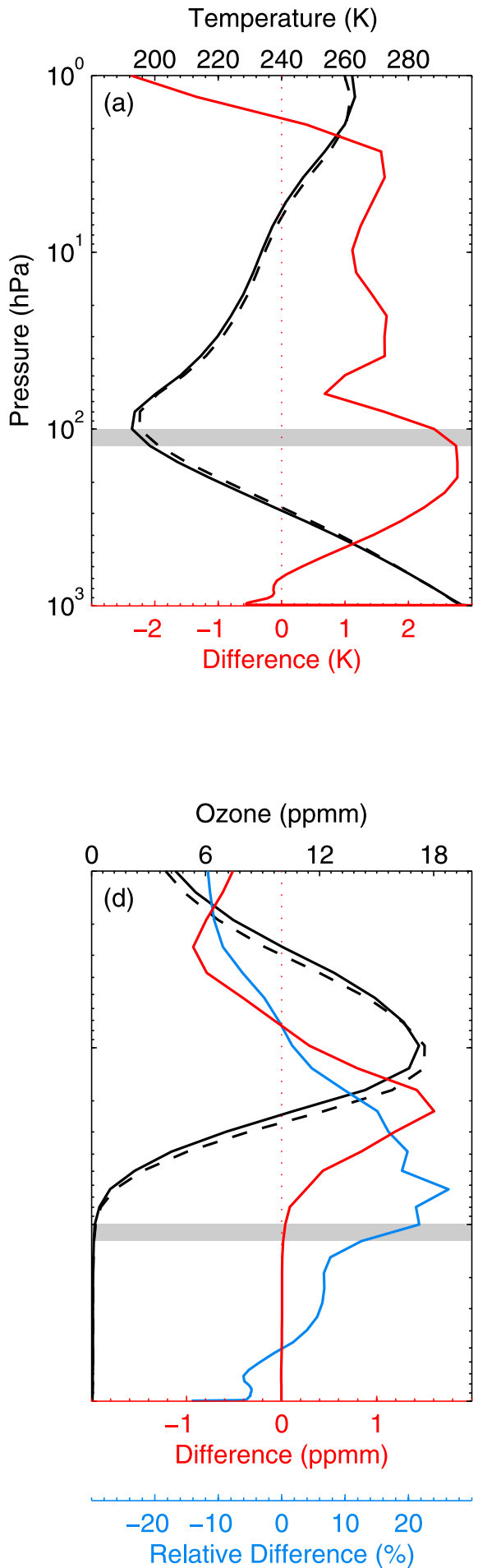

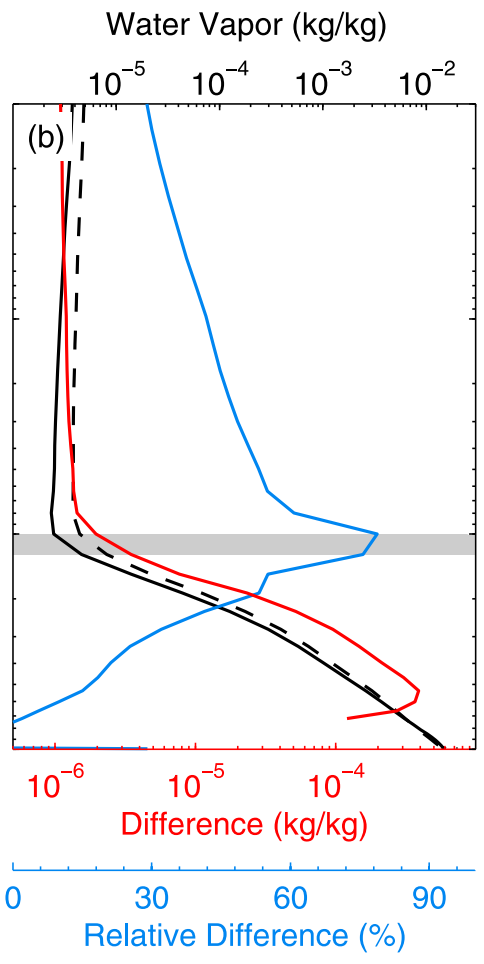

Cloud Fraction
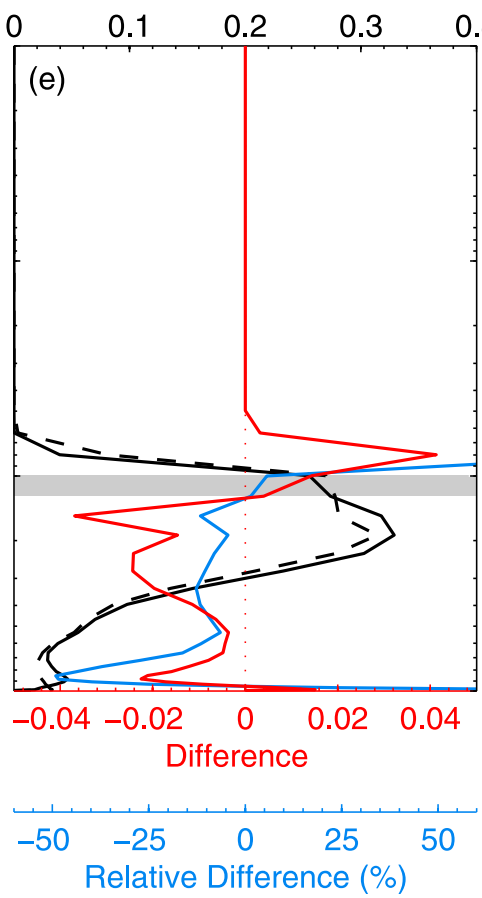

Relative Humdity (\%)
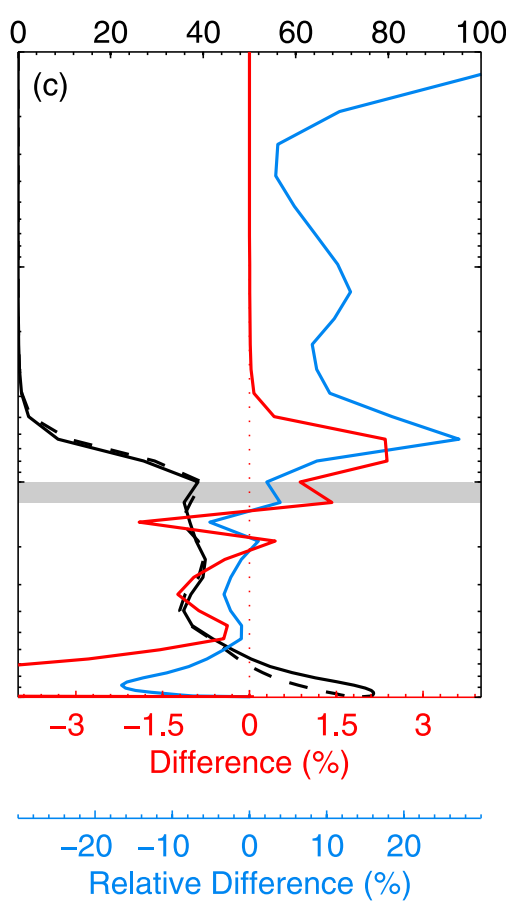

$\mathrm{W}^{*}(\mathrm{~mm} / \mathrm{s})$
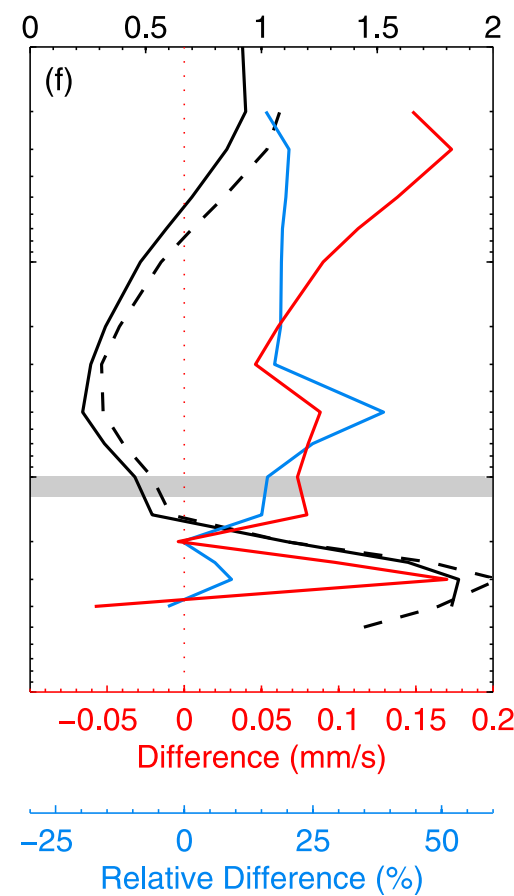

FIG. 8. As in Fig. 5, but for the tropopause-relative coordinate. The gray shading indicates the 100-hPa layer where the composite tropopause is located.

rate change. The longwave part, on the other hand, shows less warming or even cooling when $\mathrm{CO}_{2}$ increases from a high base value. Diverse responses in longwave heating rate are seen among different radiative transfer models when the $\mathrm{CO}_{2}$ concentration is higher than $600 \mathrm{ppm}$. Even for a moderate $\mathrm{CO}_{2}$ increase from 400 to $600 \mathrm{ppm}$, the difference in longwave heating rate increase at the tropopause among radiative transfer models is greater 


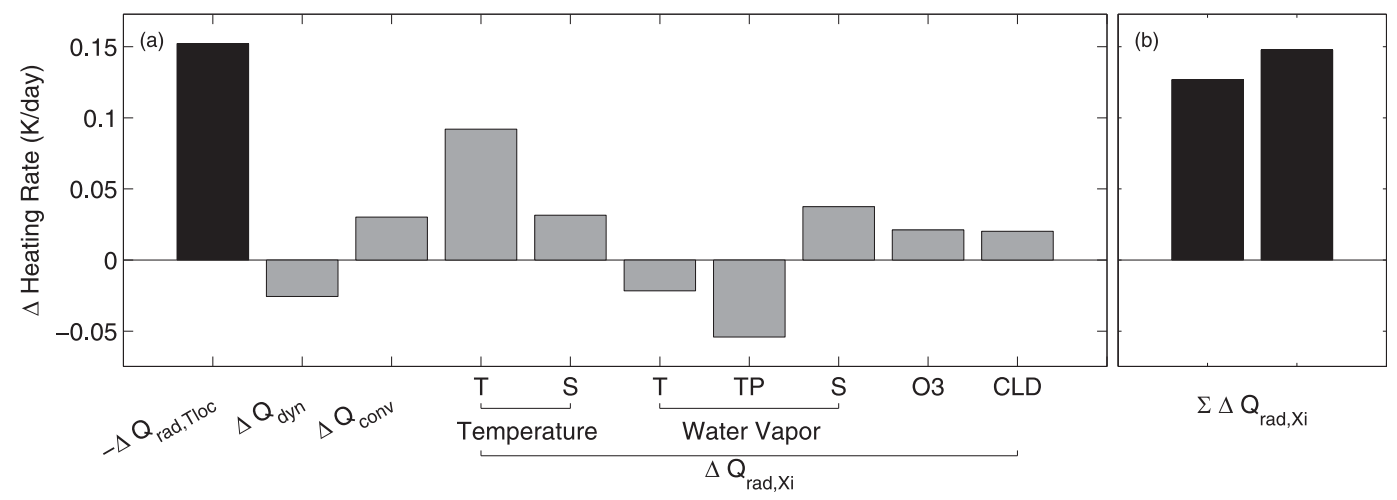

FIG. 9. As in Fig. 4, but for the composite tropopause.

than $40 \%$. Note that the long radiative relaxation time near the tropopause (Fels 1982; Ramaswamy and Ramanathan 1989; Thuburn and Craig 2002; Hartmann and Larson 2002; Gettelman et al. 2004) implies a large temperature response to any change in the heating rate. Therefore, an error in the heating rate of similar magnitude would then translate into a larger error in temperature at the tropopause than at other levels.

The radiative warming at the tropopause from the warmer troposphere is largely determined by temperature change at the tropical upper troposphere. While the tropical upper-tropospheric warming is a robust feature of the global warming simulated virtually by all models (Ramaswamy et al. 2006), recent studies show that the magnitudes of the warming differ more than threefold among CMIP3 and CMIP5 models (Fu et al. 2011; Po-Chedley and Fu 2012). This large intermodel spread may be attributed to the large uncertainty in the cumulus parameterization as well as the dependence on the detailed sea surface temperature patterns (Flannaghan et al. 2014). Lin and Fu (2013) further show that the acceleration of the stratospheric circulation is also tightly coupled to the warming at the tropical upper troposphere. Note that about half of the influence from stratospheric circulation change is realized through changing ozone concentration. This mechanism will be absent in many CMIP3 and CMIP5 models with prescribed ozone.

While in general there is uncertainty regarding cloud properties and their effects in models, convection and clouds play relatively minor roles in altering tropopause temperature in this model. Previous studies suggest that the upward shift of clouds is a robust response to global warming (Hartmann and Larson 2002; Zelinka and Hartmann 2010). This, however, does not necessarily translate to a robust change at the tropopause. If convection and cloud tops are well below the tropopause, any shift in convection or clouds would exert negligible effect on the tropopause. Thuburn and Craig (2002) showed that the radiation from the $15 \mu \mathrm{m} \mathrm{CO}$ band plays an important role in separating the cold-point tropopause and the convection top. This, again, suggests the importance to improve the accuracy of radiative transfer calculations, especially near the tropopause region.

\section{Summary and conclusions}

Change in the tropical tropopause is an important consequence of the GHG-induced global climate change. Here we investigate the tropical tropopause change in

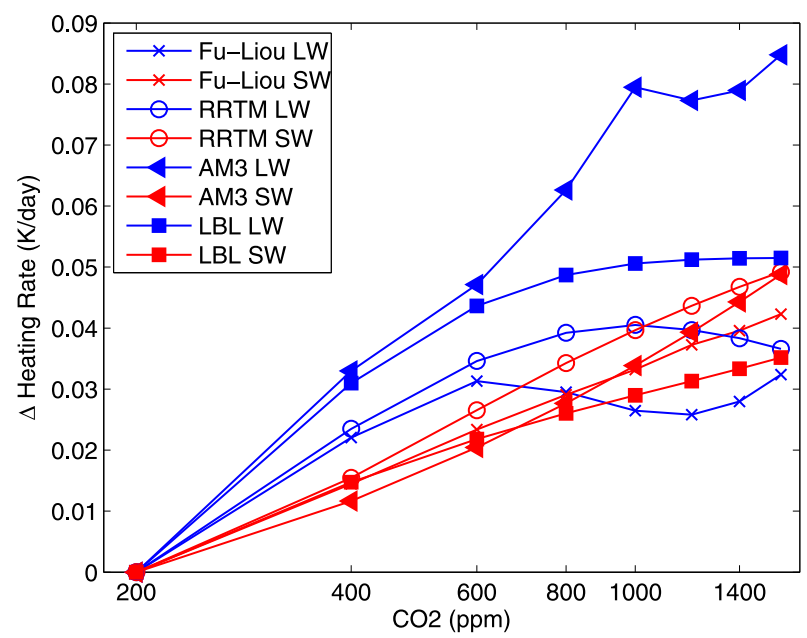

FIG. 10. Longwave (blue) and shortwave (red) heating rate changes at the tropopause as $\mathrm{CO}_{2}$ concentration increases from $200 \mathrm{ppm}$. The heating rates are calculated using AM3 radiative transfer code (triangle), Fu-Liou radiative transfer code (cross), the RRTM (circle), and the RFM line-by-line code (square). The radiative calculations are done using the tropical mean profiles from the control simulation, and are carried out at the equinox under clear-sky aerosol-free conditions. See text for more explanation. 
response to a quadrupling $\mathrm{CO}_{2}$ with fixed SST and a uniform SST warming of $4 \mathrm{~K}$ with GFDL AM3. The tropopause becomes warmer in both experiments. The tropopause height (pressure) shifts upward following surface warming, but remains unchanged as $\mathrm{CO}_{2}$ increases.

We perform a detailed heat budget analysis at the tropopause to distinguish and quantify the contributions from different radiative, dynamic, and thermodynamic processes to the tropopause temperature change. The heat budget analysis shows that in the $4 \times \mathrm{CO} 2$ experiment, the tropopause warming is mainly caused by the direct radiative effect from $\mathrm{CO}_{2}$ increase. In the 4KSST experiment, the largest contributor at $100 \mathrm{hPa}$ is the radiative warming from a warmer troposphere. The temperature change at $63 \mathrm{hPa}$, on the other hand, is dominated by cooling induced by a stronger Brewer-Dobson circulation, both dynamically and radiatively via changing ozone. Taking the tropopause height change into account, we redo the heat budget analysis in the tropopause-relative coordinate for the 4KSST experiment. The composite heat budget reveals that changes in tropospheric and stratospheric temperature, moistening in the stratosphere, and changes in ozone, convection, and clouds all lead to a warming of the tropopause, with the warmer troposphere being the largest contributor. The tropopause is cooled by stronger upwelling across the tropopause and the moistening in the troposphere and at the tropopause, among which the wetter tropopause contributes the most. We substantiate that the radiative warming at the tropopause from $\mathrm{CO}_{2}$ increase and the warmer troposphere are the dominant contributors to tropical tropopause change under global warming, and that intermodel differences may be traced back to a number of key processes (such as radiative transfer scheme, the tropical upper-tropospheric warming, ozone transport, and the convection top climatology).

Acknowledgments. This report was prepared by $\mathrm{Pu}$ Lin under Award NA14OAR4320106 from the National Oceanic and Atmospheric Administration, U.S. Department of Commerce. The statements, findings, conclusions, and recommendations are those of the author(s) and do not necessarily reflect the views of the National Oceanic and Atmospheric Administration, or the U.S. Department of Commerce.

\section{REFERENCES}

Anderson, J. L., and Coauthors, 2004: The new GFDL global atmosphere and land model AM2-LM2: Evaluation with prescribed SST simulations. J. Climate, 17, 4641-4673, doi:10.1175/JCLI-3223.1.

Andrews, T., and P. M. Forster, 2008: $\mathrm{CO}_{2}$ forcing induces semidirect effects with consequences for climate feedback interpretations. Geophys. Res. Lett., 35, L04802, doi:10.1029/ 2007 GL032273.

Austin, J., and T. J. Reichler, 2008: Long-term evolution of the cold point tropopause: Simulation results and attribution analysis. J. Geophys. Res., 113, D00B10, doi:10.1029/2007JD009768.

Barnett, J. J., J. T. Houghton, and J. A. Pyle, 1975: The temperature dependence of the ozone concentration near the stratosphere. Quart. J. Roy. Meteor. Soc., 101, 245-257, doi:10.1002/qj.49710142808.

Birner, T., A. Dörnbrack, and U. Schumann, 2002: How sharp is the tropopause at midlatitudes? Geophys. Res. Lett., 29, 1700, doi:10.1029/2002GL015142.

Butchart, N., 2014: The Brewer-Dobson circulation. Rev. Geophys., 52, 157-184, doi:10.1002/2013RG000448.

Clough, S. A., M. W. Shephard, E. J. Mlawer, J. S. Delamere, M. J. Iacono, K. Cady-Pereira, S. Boukabara, and P. D. Brown, 2005: Atmospheric radiative transfer modeling: A summary of the AER codes. J. Quant. Spectrosc. Radiat. Transfer, 91, 233 244, doi:10.1016/j.jqsrt.2004.05.058.

Colman, R. A., and B. J. McAvaney, 1997: A study of general circulation model climate feedbacks determined from perturbed sea surface temperature experiments. J. Geophys. Res., 102, 19383-19 402, doi:10.1029/97JD00206.

— and - 2011: On tropospheric adjustment to forcing and climate feedbacks. Climate Dyn., 36, 1649-1658, doi:10.1007/ s00382-011-1067-4.

Donner, L. J., and Coauthors, 2011: The dynamical core, physical parameterizations, and basic simulation characteristics of the atmospheric component AM3 of the GFDL global coupled model CM3. J. Climate, 24, 3484-3519, doi:10.1175/ 2011JCLI3955.1.

Emanuel, K., S. Solomon, D. Folini, S. Davis, and C. Cagnazzo, 2013: Influence of tropical tropopause layer cooling on Atlantic hurricane activity. J. Climate, 26, 2288-2301, doi:10.1175/ JCLI-D-12-00242.1.

Fels, S. B., 1982: A parameterization of scale-dependent radiative damping rates in the middle atmosphere. J. Atmos. Sci., 39, 1141-1152, doi:10.1175/1520-0469(1982)039<1141: APOSDR $>2.0 . \mathrm{CO} ; 2$.

_ J. D. Mahlman, M. D. Schwarzkopf, and R. W. Sinclair, 1980: Stratospheric sensitivity to perturbations in ozone and carbon dioxide: Radiative and dynamical response. J. Atmos. Sci., 37, 2265-2297, doi:10.1175/1520-0469(1980)037<2265: SSTPIO $>2.0 . \mathrm{CO} ; 2$.

Flannaghan, T. J., S. Fueglistaler, I. M. Held, S. Po-Chedley, B. Wyman, and M. Zhao, 2014: Tropical temperature trends in atmospheric general circulation model simulations and the impact of uncertainties in observed SSTs. J. Geophys. Res. Atmos., 119, 13 327-13 337, doi:10.1002/2014JD022365.

Freidenreich, S. M., and V. Ramaswamy, 1999: A new multipleband solar radiative parameterization for general circulation models. J. Geophys. Res., 104, 31389-31 409, doi:10.1029/ 1999JD900456.

Fu, Q., and K.-N. Liou, 1992: On the correlated $k$-distribution method for radiative transfer in nonhomogenous atmospheres. J. Atmos. Sci., 49, 2139-2156, doi:10.1175/1520-0469(1992)049<2139: OTCDMF $>2.0 . \mathrm{CO} ; 2$.

_ S. Manabe, and S. M. Johanson, 2011: On the warming in the tropical upper troposphere: Models versus observations. Geophys. Res. Lett., 38, L15704, doi:10.1029/2011GL048101.

Fueglistaler, S., A. E. Dessler, T. J. Dunkerton, I. Folkins, Q. Fu, and P. W. Mote, 2009: Tropical tropopause layer. Rev. Geophys., 47, RG1004, doi:10.1029/2008RG000267. 
— , P. H. Haynes, and P. M. Forster, 2011: The annual cycle in lower stratospheric temperature revisited. Atmos. Chem. Phys., 11, 3701-3711, doi:10.5194/acp-11-3701-2011.

Gettelman, A., P. M. de F. Forster, M. Fujiwara, Q. Fu, H. Vömel, L. K. Gohar, C. Johanson, and M. Ammerman, 2004: Radiative balance of the tropical tropopause layer. J. Geophys. Res., 109, D07103, doi:10.1029/2003JD004190.

__ , and Coauthors, 2010: Multimodel assessment of the upper troposphere and lower stratosphere: Tropics and global trends. J. Geophys. Res., 115, D00M08, doi:10.1029/ 2009JD013638.

Hartmann, D. L., and K. Larson, 2002: An important constraint on tropical cloud-climate feedback. Geophys. Res. Lett., 29, 1951, doi:10.1029/2002GL015835.

_ J. R. Holton, and Q. Fu, 2001: The heat balance of the tropical tropopause, cirrus, and stratospheric dehydration. Geophys. Res. Lett., 28, 1969-1972, doi:10.1029/2000GL012833.

Kawatani, Y., K. Hamilton, and A. Noda, 2012: The effects of changes in sea surface temperature and $\mathrm{CO}_{2}$ concentration on the quasi-biennial oscillation. J. Atmos. Sci., 69, 1734-1749, doi:10.1175/JAS-D-11-0265.1.

Kim, J., K. M. Grise, and S.-W. Son, 2013: Thermal characteristics of the cold-point tropopause region in CMIP5 models. J. Geophys. Res. Atmos., 118, 8827-8841, doi:10.1002/jgrd.50649.

Kodama, C., T. Iwasaki, K. Shibata, and S. Yukimoto, 2007: Changes in the stratospheric mean meridional circulation due to increased $\mathrm{CO}_{2}$ : Radiation- and sea surface temperatureinduced effects. J. Geophys. Res., 112, D16103, doi:10.1029/ 2006JD008219.

Li, Y., and D. W. J. Thompson, 2013: The signature of the stratospheric Brewer-Dobson circulation in tropospheric clouds. J. Geophys. Res. Atmos., 118, 3486-3494, doi:10.1002/ jgrd.50339.

Lin, P., and Q. Fu, 2013: Changes in various branches of the Brewer-Dobson circulation from an ensemble of chemistry climate models. J. Geophys. Res., 118, 73-84, doi:10.1029/ 2012JD018813.

_- Y. Ming, and V. Ramaswamy, 2015: Tropical climate change control of the lower stratospheric circulation. Geophys. Res. Lett., 42, 941-948, doi:10.1002/2014GL062823.

Liou, K. N., 2002: An Introduction to Atmospheric Radiation. 2nd ed. International Geophysical Series, Vol. 84, Academic Press, 583 pp.

Manabe, S., and R. T. Wetherald, 1967: Thermal equilibrium of the atmosphere with a given distribution of relative humidity. J. Atmos. Sci. 24, 241-259, doi:10.1175/1520-0469(1967)024<0241: TEOTAW $>2.0 . \mathrm{CO} ; 2$.

McLandress, C., T. G. Shepherd, M. C. Reader, D. A. Plummer, and K. P. Shine, 2014: The climate impact of past changes in halocarbons and $\mathrm{CO}_{2}$ in the tropical UTLS region. J. Climate, 27, 8646-8660, doi:10.1175/JCLI-D-14-00232.1.

Mlawer, E. J., S. J. Taubman, P. D. Brown, M. J. Iacono, and S. A. Clough, 1997: Radiative transfer for inhomogeneous atmospheres: RRTM, a validated correlated- $k$ model for the longwave. J. Geophys. Res., 102, 16 663-16 682, doi:10.1029/97JD00237.

Mote, P. W., and Coauthors, 1996: An atmospheric tape recorder: The imprint of tropical tropopause temperature on stratospheric water vapor. J. Geophys. Res., 101, 3989-4006, doi:10.1029/95JD03422.

Oman, L., D. W. Waugh, S. Pawson, R. S. Stolarski, and P. A. Newman, 2009: On the influence of anthropogenic forcings on changes in the stratospheric mean age. J. Geophys. Res., 114, D03105, doi:10.1029/2008JD010378.
Pan, L. L., W. J. Randel, B. L. Gary, M. J. Mahoney, and E. J. Hintsa, 2004: Definitions and sharpness of the extratropical tropopause: A trace gas perspective. J. Geophys. Res., 109, D23103, doi:10.1029/2004JD004982.

Pincus, R., H. W. Barker, and J. Morcrette, 2003: A fast, flexible, approximate technique for computing radiative transfer in inhomogeneous cloud fields. J. Geophys. Res., 108, 4376, doi:10.1029/2002JD003322.

Po-Chedley, S., and Q. Fu, 2012: Discrepancies in tropical upper tropospheric warming between atmospheric circulation models and satellites. Environ. Res. Lett., 7, 044018, doi:10.1088/1748-9326/7/4/044018.

Ramaswamy, V., and V. Ramanathan, 1989: Solar absorption by cirrus clouds and the maintenance of the tropical upper troposphere thermal structure. J. Atmos. Sci., 46, 2293-2310, doi:10.1175/1520-0469(1989)046<2293:SABCCA > 2.0.CO;2.

— M. D. Schwarzkopf, and W. J. Randel, 1996: Fingerprint of ozone depletion in the spatial and temporal pattern of recent lower stratospheric cooling. Nature, 382, 616-618, doi:10.1038/ $382616 \mathrm{a} 0$.

, J. W. Hurrell, and G. A. Meehl, 2006: Why do temperatures vary vertically (from the surface to the stratosphere) and what do we understand about why they might vary and change over time? Temperature Trends in the Lower Atmosphere: Steps for Understanding and Reconciling Differences, T. R. Karl et al., Eds., U.S. Climate Change Science Program, 15-28.

Randel, W. J., and E. J. Jensen, 2013: Physical processes in the tropical tropopause layer and their roles in a changing climate. Nat. Geosci., 6, 169-176, doi:10.1038/ngeo1733.

Rosenlof, K. H., 1995: Seasonal cycle of the residual mean meridional circulation in the stratosphere. J. Geophys. Res., 100, 5173-5191, doi:10.1029/94JD03122.

Santer, B. D., and Coauthors, 2003: Contributions of anthropogenic and natural forcing to recent tropopause height changes. Science, 301, 479-483, doi:10.1126/science.1084123.

Schwarzkopf, M. D., and V. Ramaswamy, 1999: Radiative effects of $\mathrm{CH}_{4}, \mathrm{~N}_{2} \mathrm{O}$, halocarbons and the foreign-broadened $\mathrm{H}_{2} \mathrm{O}$ continuum: A GCM experiment. J. Geophys. Res., 104, 94679488, doi:10.1029/1999JD900003.

Seidel, D. J., and W. J. Randel, 2006: Variability and trends in the global tropopause estimated from radiosonde data. J. Geophys. Res., 111, D21101, doi:10.1029/2006JD007363.

Shepherd, T. G., 2002: Issues in stratosphere-troposphere coupling. J. Meteor. Soc. Japan, 80, 769-792, doi:10.2151/jmsj.80.769.

Sherwood, S. C., S. Bony, O. Boucher, C. Bretherton, P. M. Forster, J. M. Gregory, and B. Stevens, 2015: Adjustments in the forcing-feedback framework for understanding climate change. Bull. Amer. Meteor. Soc., 96, 217-228, doi:10.1175/ BAMS-D-13-00167.1.

Shine, K. P., and Coauthors, 2003: A comparison of modelsimulated trends in stratospheric temperatures. Quart. J. Roy. Meteor. Soc., 129, 1565-1588, doi:10.1256/qj.02.186.

Soden, B. J., I. M. Held, R. Colman, K. M. Shell, J. T. Kiehl, and C. A. Shields, 2008: Quantifying climate feedbacks using radiative kernels. J. Climate, 21, 3504-3520, doi:10.1175/2007JCLI2110.1.

Solomon, S., K. H. Rosenlof, P. W. Robert, J. S. Daniel, S. M. Davis, T. J. Sanford, and G.-K. Plattner, 2010: Contribution of stratospheric water vapor to decadal changes in the rate of global warming. Science, 327, 1219-1223, doi:10.1126/ science. 1182488

Thuburn, J., and G. C. Craig, 2002: On the temperature structure of the tropical substratosphere. J. Geophys. Res., 107, 4017, doi:10.1029/2001JD000448. 
Virts, K. S., J. M. Wallace, Q. Fu, and T. P. Ackerman, 2010: Tropical tropopause transition layer cirrus as represented by CALIPSO lidar observation. J. Atmos. Sci., 67, 3113-3129, doi:10.1175/2010JAS3412.1.

Wang, S., S. J. Camargo, A. H. Sobel, and L. M. Polvani, 2014: Impact of the tropopause temperature on the intensity of tropical cyclones: An idealized study using a mesoscale model. J. Atmos. Sci., 71, 4333-4348, doi:10.1175/JAS-D-14-0029.1.

Wetherald, R. T., and S. Manabe, 1988: Cloud feedback processes in a GCM. J. Atmos. Sci., 45, 1397-1416, doi:10.1175/ 1520-0469(1988)045<1397:CFPIAG >2.0.CO;2.
Yang, Q., Q. Fu, J. Austin, A. Gettelman, F. Li, and H. Vömel, 2008: Observationally derived and general circulation model simulated tropical stratospheric upward mass fluxes. J. Geophys. Res., 113, D00B07, doi:10.1029/2008JD009945.

Zelinka, M. D., and D. L. Hartmann, 2010: Why is longwave cloud feedback positive? J. Geophys. Res., 115, D16117, doi:10.1029/ 2010JD013817.

, S. A. Klein, K. E. Taylor, T. Andrews, M. J. Webb, J. M. Gregory, and P. M. Forster, 2013: Contributions of different cloud types to feedbacks and rapid adjustments in CMIP5. J. Climate, 26, 5007-5027, doi:10.1175/JCLI-D-12-00555.1. 